\title{
Comparative analysis of corrosion inhibition effects of mebendazole (MBZ) on mild steel in three different sulphuric acid concentrations
}

\author{
F.O. Edoziuno, ${ }^{1 *}$ A.A. Adediran, ${ }^{2}$ B.U. Odoni, ${ }^{1}$ M. Oki ${ }^{2}$ and O.S. Adesina ${ }^{2}$ \\ ${ }^{1}$ Department of Metallurgical Engineering, Delta State Polytechnic, Ogwashi-Uku, Nigeria \\ ${ }^{2}$ Department of Mechanical Engineering, Landmark University, Omu-Aran, PMB 1001, \\ Kwara State, Nigeria \\ *E-mail: francisedoziuno@gmail.com
}

\begin{abstract}
This study compares the electrochemical corrosion inhibition properties of various concentrations of MBZ (0-2.5 g/L) for mild steel in $0.5,1.0$ and $1.5 \mathrm{M}$ sulphuric acid using potentiodynamic polarization (PDP) technique. Mebendazole was found to effectively impede the surface degradation of mild steel in the various concentrations of $\mathrm{H}_{2} \mathrm{SO}_{4}$ studied with maximum inhibition efficiencies of 97, 98 and 99\% respectively. Inhibition efficiencies increased to these maximum values at $1.0,1.5$ and $1.0 \mathrm{~g} / \mathrm{L}$ inhibitor concentrations respectively, before decreasing with subsequent increase in the concentrations of MBZ. Potentiodynamic polarization results suggest the mixed type inhibitor nature of MBZ in sulphuric acid. Corrosion current was observed to increase with acid concentration and significantly decreases with the addition of the inhibitor. Polarization resistance decreased as acid concentrations increased and was higher for higher inhibitor concentrations. From the results, corrosion current and corrosion rate were very high for the corrosion media without MBZ addition, while the polarization resistance was very minimal for the corrosion media without MBZ addition. There is a significant change to relatively smooth morphology, in the SEM micrographs of the mild steel immersed in the test solution with the MBZ, as a result of the interaction of MBZ with the active sites on the surface of the metal, which resulted in an enhanced surface coverage of MBZ molecules on the mild steel.
\end{abstract}

Keywords: benzimidazole, polarization, mild steel, acid corrosion, mebendazole, polarization resistance.

Received: April 6, 2020. Published: September 3, 2020

doi: $\underline{10.17675 / 2305-6894-2020-9-3-17}$

\section{Introduction}

The corrosion of mild steel occurs owing to electrochemical reactions with its environment $[1,2]$. To mitigate these reactions and prolong the life span of mild steel in various service environments, corrosion inhibitors are needed amongst other intervention techniques. Corrosion inhibitors are chemical substances that when introduced in measured quantities to corrosion systems, retard electrochemical reactions or corrosion rates of metals in that 
environment, thus, inhibitors are corrosion retarding substances [1,3-5]. The inhibition efficiency of most chemical substances depends largely on the manner of interaction with the surface of the substrate and their molecular structure [6,7]. Inhibitors often work by adsorption on the metallic surface $[8,9]$, thereby conferring protection on the surface of the metal by forming a surface covering film. Suitable means of applying inhibitors are by spreading from a solution or by dispersion. Others are introduced during the formulation of a protective coating. Only a small number of chemical substances investigated for corrosion inhibition properties are employed in real life corrosion inhibition applications. This is in part because the desirable properties for an inhibitor transcend those simply related to protection of metal in service environments. Recent global ecological campaign and strict enforcement of environmental regulations and sanctions make consideration of cost, availability, toxicity and environmental benignity of great significance [10-15]. Therefore, much attention is now focused on organic inhibitors, which are biodegradable and without any or low toxic effects in the intended service environment. Various drugs have been investigated as novel, biodegradable and synthetic inhibitors with promising results $[9,16]$. Pertinent research publications reviewed in the course of this investigation disclosed the successful application of the derivatives of benzimidazole as efficient nitrogenous heterocyclic corrosion inhibitor for steel in acidic service and various other environments [5, 17-24]. Mebendazole is methyl-5-benzoyl-2-benzimidazole carbamate, a non-toxic and biodegradable synthetic benzimidazole derivative used in therapeutic treatments as anthelmintic drug. Its molecular formula and molecular weight are $\mathrm{C}_{16} \mathrm{H}_{13} \mathrm{~N}_{3} \mathrm{O}_{3}$ and $295.29752 \mathrm{~g} / \mathrm{mol}$ [25] respectively. It has a planar structure with two anchoring sites at $\mathrm{sp}^{2}$ hybridized nitrogen, a lone pair of electrons and aromatic rings [22, 23]. Its molecular structure is given in Figure 1. This article attempts a comparative analysis of the corrosion inhibitive influence of various concentrations of mebendazole on mild steel in 0.5, 1.0 and $1.5 \mathrm{M}$ sulphuric acid solutions using potentiodynamic polarization (PDP) technique.

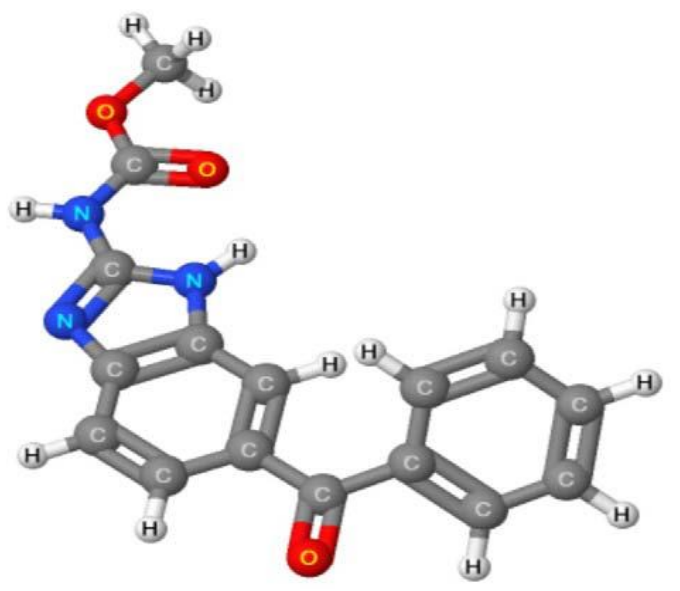

Figure 1. 3D Optimized molecular structure of methyl-5-benzoyl-2-benzimidazole carbamate (mebendazole) [25]. 


\section{Research methodology}

Electrochemical experiments were performed at ambient temperature in $0.5,1.0$ and $1.5 \mathrm{M}$ concentration of $\mathrm{H}_{2} \mathrm{SO}_{4}$, prepared with double distilled deionized water in the absence or presence of pre-determined quantity of mebendazole (MBZ) inhibitor $(0,0.5,1.0,1.5,2.0$ and $2.5 \mathrm{~g} / \mathrm{L}$ ). An Autolab potentiostat/galvanostat, VersaSTAT 4 Electrochemical System, controlled from a suitably equipped PC by a Universal Serial Bus (USB) interface using the VersaStudio electrochemistry software package was used to perform the electrochemical experiments. The electrochemical test parameters and procedure has been described in details elsewhere [2]. The values of the electrochemical parameters and properties obtained from the electrochemical test are presented in Table 1. The electrochemical effects of the inhibitor on the mild steel coupons was further studied by examining the surface morphology before and after the introduction of MBZ in the acid media using scanning electron microscopy technique. A Phenom Pro X Model SEM equipment was employed for this purpose. The inhibition efficiency, $\eta$ was determined using the mathematical relation given in Equation 1, while the polarization resistance $\left(R_{\mathrm{P}}\right)$ was calculated using the simplified Stern-Geary equation (Equation 2).

$$
\begin{gathered}
\eta=\frac{i_{\text {corr }_{\mathrm{c}}}-i_{\text {corr }_{\mathrm{i}}}}{i_{\text {corr }_{\mathrm{c}}}} \times 100 \\
R_{\mathrm{P}}=\frac{B}{i_{\text {corr }}}
\end{gathered}
$$

where, $i_{\text {corr }}$ and $i_{\text {corr }_{\mathrm{c}}}$ represent the corrosion current densities of the working electrodes in the absence and the presence of specified amount of the inhibitor respectively. $B$ is a constant of proportionality determined empirically from the anodic and cathodic slopes of the Tafel plot.

\section{Results and Discussion}

\subsection{Potentiodynamic polarization (PDP) measurements}

It could be observed from the polarization results in Table 1 that the addition of MBZ inhibitor to the $\mathrm{H}_{2} \mathrm{SO}_{4}$ solution has a moderately pronounced effect on both the anodic and cathodic half reactions. The potentiodynamic parameters presented in Table 1 were obtained by the extrapolation of the Tafel plots. The polarization tests show that MBZ displaced the $E_{\text {corr }}$ significantly, thus remarkedly altering the corrosion electrochemical reactions. Furthermore, changes in the cathodic and anodic Tafel constants in the presence of mebendazole in contrast with the blank corrodent solution indicate the inhibition of the cathodic and the anodic reactions associated with the corrosion process by the surface shielding effect of the protective film formed by the inhibitor [4]. The protective role of the inhibitor may be related to the adsorption of its molecules and formation of a surface film 
on the mild steel electrode [4]. This is further indicated by the values of the $E_{\text {corr }}, i_{\text {corr }}$ and polarization resistance $\left(R_{\mathrm{P}}\right)$ obtained for the tests with the inhibitor when compared with the values for the tests carried out without the addition of the inhibitor. The $i_{\text {corr }}$ for the uninhibited test solution increases as the acid concentration increased from 0.5 to $1.5 \mathrm{M}$. The polarization results indicate similar effects on both anodic and cathodic Tafel constants for all the inhibitor and acid concentrations examined. This signifies that MBZ performed as a mixed type inhibitor [4]. The control experiment that had no added inhibitor displayed the highest corrosion rate in comparison with those which contained various inhibitor concentrations as portrayed by increases in the polarization resistance values. It could be deduced from the polarization results that the MBZ behaved as mixed type inhibitor, since the displacement of $E_{\text {corr }}$ obtained with reference to the test without the inhibitor (Table 1) is less than $85 \mathrm{mV}$ for all the sulphuric acid and inhibitor concentrations investigated $[23,26,27]$.

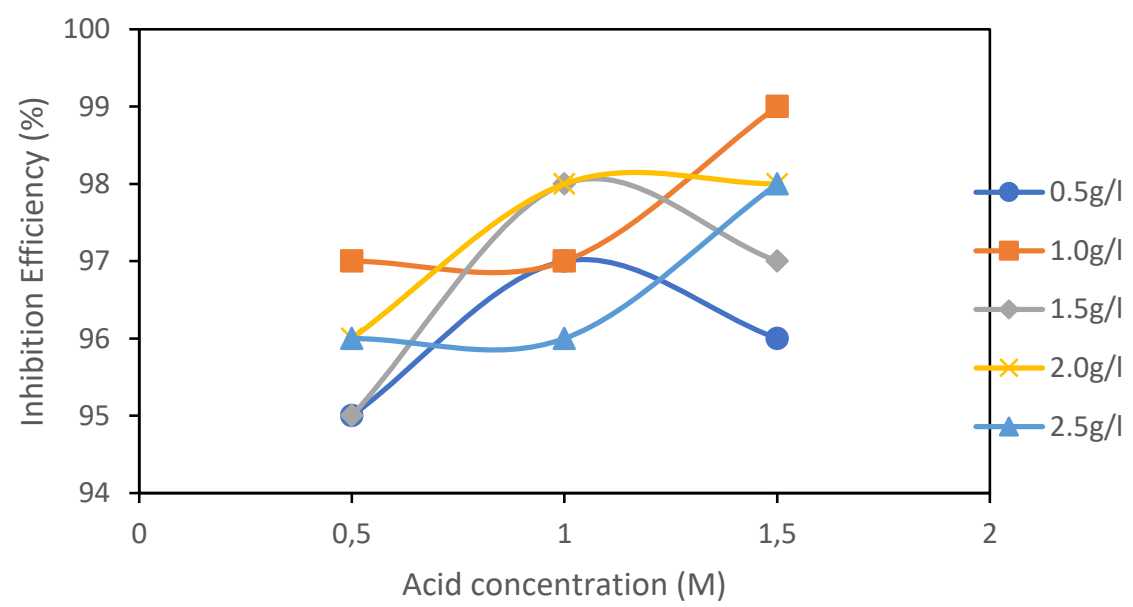

Figure 2. Plot of inhibition efficiency (\%) of MBZ against acid concentration (M).

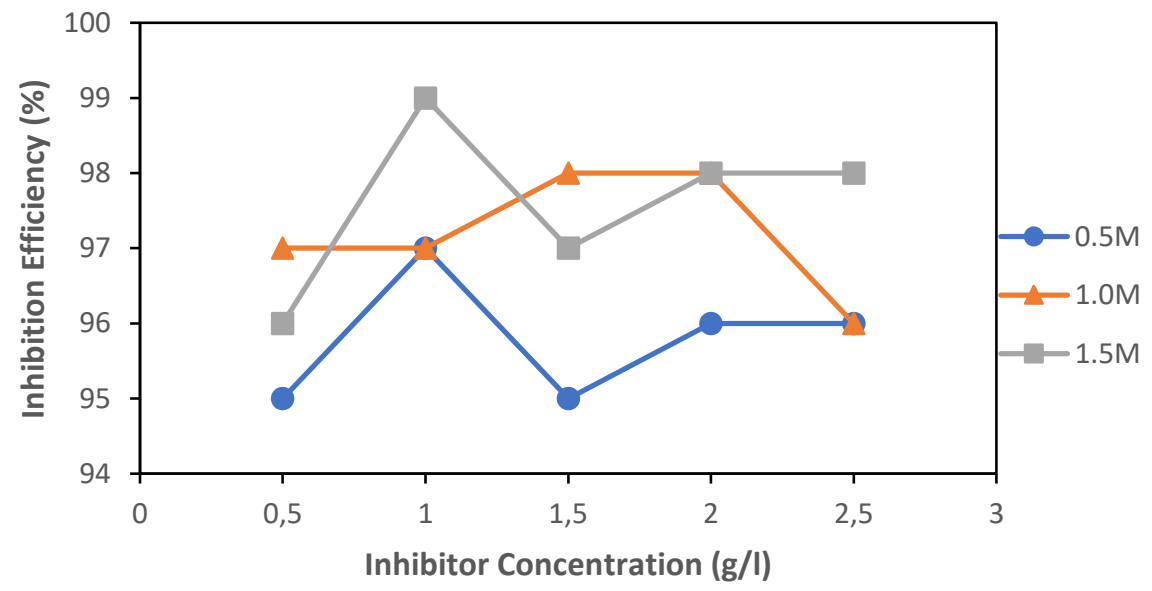

Figure 3. Plot of inhibition efficiency (\%) of MBZ against the inhibitor concentration (g/L). 


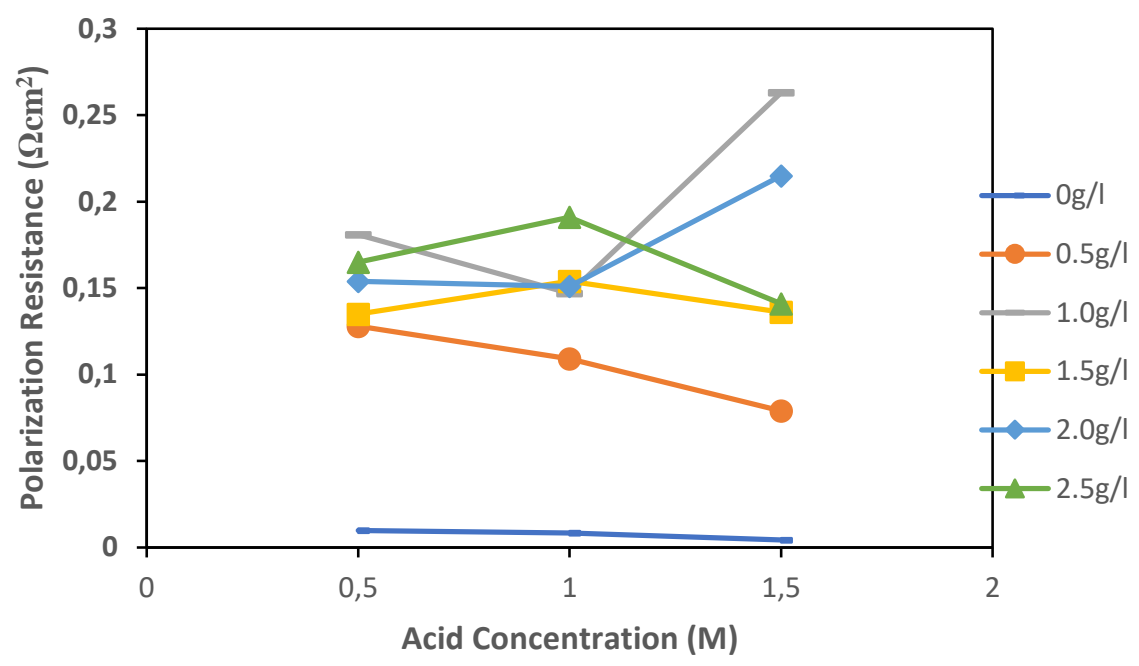

Figure 4. Plot of polarization resistance $\left(\Omega \cdot \mathrm{cm}^{2}\right)$ against acid concentration $(\mathrm{M})$.

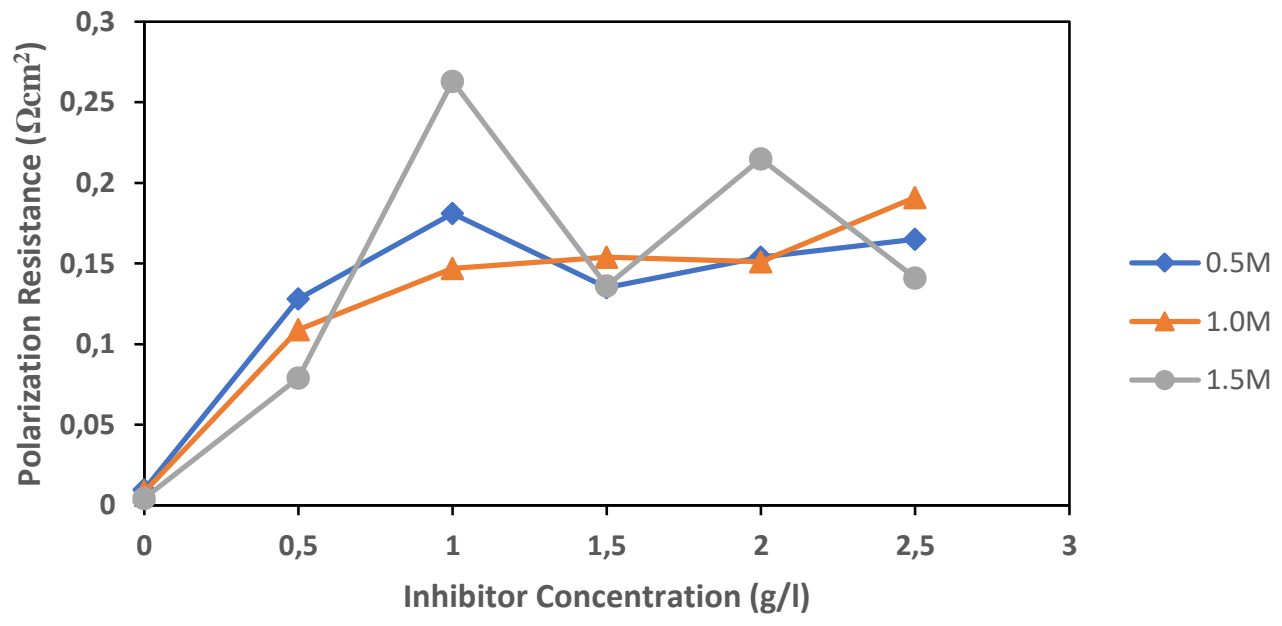

Figure 5. Plot of polarization resistance $\left(\Omega \cdot \mathrm{cm}^{2}\right)$ against inhibitor concentration $(\mathrm{g} / \mathrm{L})$.

The maximum values of corrosion inhibition efficiencies obtained from the anodic and cathodic polarization study increased as the concentration of the corroding environment increased from $0.5-1.5 \mathrm{M}$. The MBZ inhibitor remarkedly slowed the electrochemical reactions involved in the dissolution of mild steel in the various acidic environments with maximum inhibition efficiencies of $97 \%$ at $1.0 \mathrm{~g} / \mathrm{L} \mathrm{MBZ,} 98 \%$ at $1.5 \mathrm{~g} / \mathrm{L} \mathrm{MBZ}$ and $99 \%$ at $1.0 \mathrm{~g} / \mathrm{L} \mathrm{MBZ}$ for the $0.5,1.0$ and $1.5 \mathrm{M} \mathrm{H}_{2} \mathrm{SO}_{4}$ respectively. As the amount of inhibitor increased, the developing protective film covered more active sites on the surface of the mild steel and resulted in the reduction of surface area exposed to corrosive environment and thus, the corrosion rates. The relationships among the inhibition efficiency and the acid concentration, inhibition efficiency and inhibitor concentration, the polarization resistance and the acid concentration, as well as the polarization resistance and the inhibitor 
concentration are graphically presented in Figures 2, 3, 4 and 5 respectively. Generally from the graphs, polarization resistance decreases with acid concentration and increases with concentration of inhibitor. In addition, it could be seen in Table 1, that corrosion current increases with acid concentration and significantly decreases with the addition of the inhibitor.

Table 1. Potentiodynamic polarization parameters, corrosion rates and inhibition efficiencies for mild steel in $0.5,1.0$ and $1.5 \mathrm{M} \mathrm{H}_{2} \mathrm{SO}_{4}$ without and with varying concentrations of MBZ.

\begin{tabular}{|c|c|c|c|c|c|c|}
\hline $\begin{array}{l}\text { Concentration } \\
\text { of acid } \\
\text { (M) }\end{array}$ & $\begin{array}{c}\text { Concentration } \\
\text { of inhibitor } \\
(\mathrm{g} / \mathrm{L})\end{array}$ & $\begin{array}{c}I_{\text {corr }} \\
\left(\mathbf{m A} / \mathbf{c m}^{2}\right)\end{array}$ & $\begin{array}{l}E_{\text {corr }} \\
(\mathbf{m V})\end{array}$ & $\begin{array}{c}\text { Rate of } \\
\text { corrosion } \\
\text { (mm/year) }\end{array}$ & $\begin{array}{c}\text { Inhibitor } \\
\text { efficiency } \\
(\%)\end{array}$ & $\begin{array}{c}\text { Polarization } \\
\text { resistance } \\
\left(\boldsymbol{\Omega} \cdot \mathbf{c m}^{2}\right)\end{array}$ \\
\hline \multirow{6}{*}{$0.5 \mathrm{M}$} & 0.0 & 3.352 & -471 & 24.8 & - & 0.00985 \\
\hline & 0.5 & 0.179 & -442 & 1.3 & 95 & 0.128 \\
\hline & 1.0 & 0.104 & -438 & 0.8 & 97 & 0.181 \\
\hline & 1.5 & 0.156 & -452 & 1.2 & 95 & 0.135 \\
\hline & 2.0 & 0.136 & -438 & 1.0 & 96 & 0.154 \\
\hline & 2.5 & 0.138 & -464 & 1.0 & 96 & 0.165 \\
\hline \multirow{6}{*}{$1.0 \mathrm{M}$} & 0.0 & 6.422 & -453 & 47.5 & - & 0.00837 \\
\hline & 0.5 & 0.184 & -416 & 1.4 & 97 & 0.109 \\
\hline & 1.0 & 0.172 & -416 & 1.3 & 97 & 0.147 \\
\hline & 1.5 & 0.138 & -415 & 1.0 & 98 & 0.154 \\
\hline & 2.0 & 0.127 & -417 & 0.9 & 98 & 0.151 \\
\hline & 2.5 & 0.243 & -427 & 1.8 & 96 & 0.191 \\
\hline \multirow{6}{*}{$1.5 \mathrm{M}$} & 0.0 & 6.577 & -430 & 48.6 & - & 0.00438 \\
\hline & 0.5 & 0.286 & -410 & 2.1 & 96 & 0.079 \\
\hline & 1.0 & 0.062 & -408 & 0.5 & 99 & 0.263 \\
\hline & 1.5 & 0.182 & -442 & 1.3 & 97 & 0.136 \\
\hline & 2.0 & 0.119 & -451 & 0.9 & 98 & 0.215 \\
\hline & 2.5 & 0.158 & -414 & 1.2 & 98 & 0.141 \\
\hline
\end{tabular}

\subsection{Mild steel surface characterization}

From the scanning electron microscopy (SEM) image of mild steel subjected to acid environment without added inhibitor for 5 days displayed in Figure 6(a), a number of wide and deep pits can be observed on the surface. However, in the presence of MBZ inhibitor (Figure 6b), there is a significant change to relatively smooth morphology, as a result of the 
interaction of MBZ with the active sites on the surface of the metal. This resulted in an enhanced surface coverage of MBZ molecules on the mild steel, so that there is a decrease in the contact between the metal surface and the aggressive environment. The varying degrees of changes in the surface smoothness in the micrographs of Figure $6 b(a-c)$ are indicative of increased levels of inhibition efficiencies obtained in the three different sulphuric acid concentrations investigated.

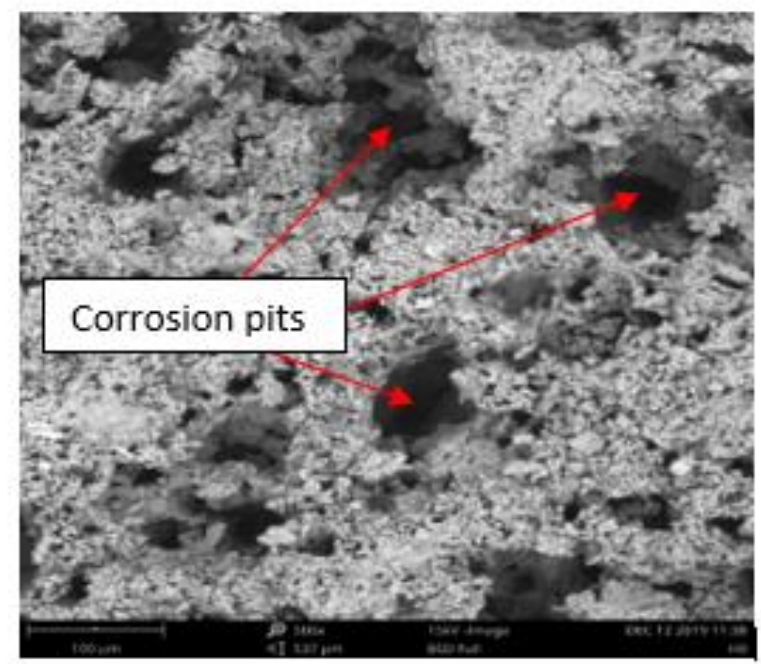

Figure 6a. SEM micrographs of mild steel coupon after 5 days immersion in $1.0 \mathrm{M} \mathrm{H}_{2} \mathrm{SO}_{4}$ without MBZ inhibitor.

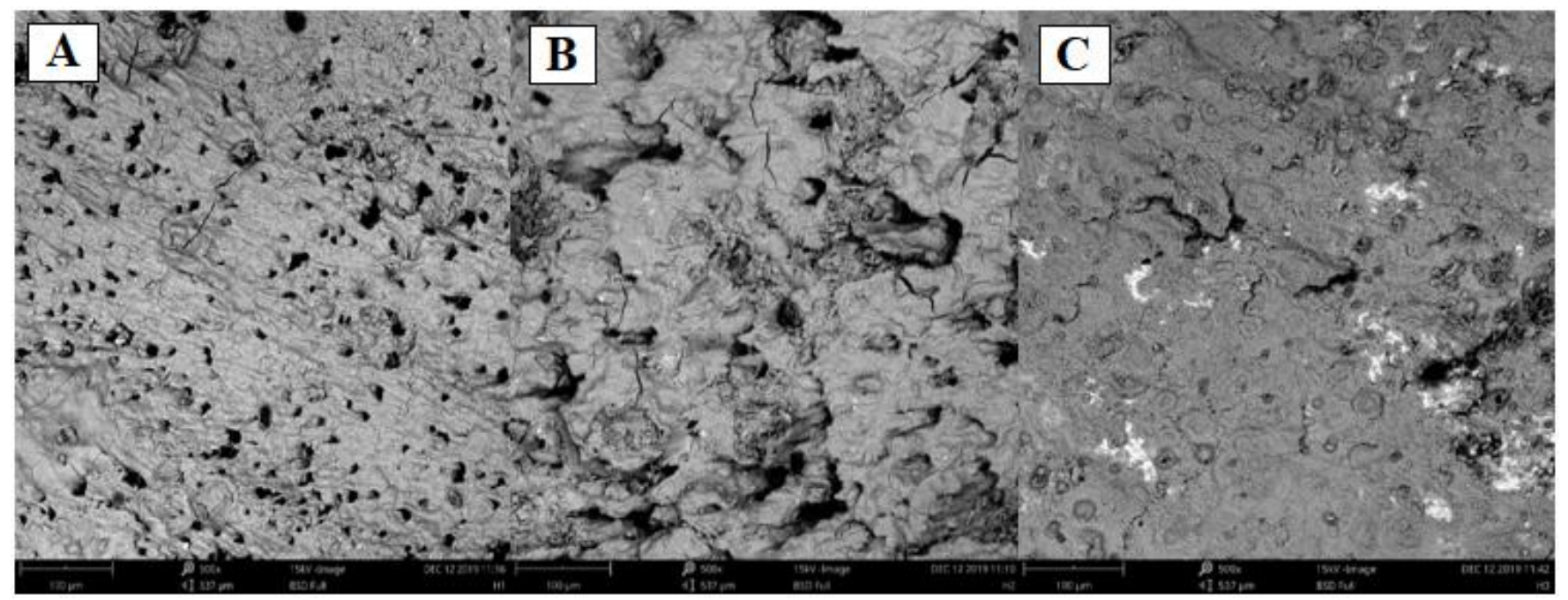

Figure 6b. SEM micrographs of mild steel coupons after immersion in (a) $0.5 \mathrm{M}$, (b) $1.0 \mathrm{M}$, and (c) $1.5 \mathrm{M} \mathrm{H}_{2} \mathrm{SO}_{4}$ solutions containing $1.5 \mathrm{~g}, 1.5 \mathrm{~g}$ and $2 \mathrm{~g}$ of MBZ inhibitor respectively. 


\section{Conclusions}

Based on the results of this comparative electrochemical study, the researchers conclude as follows:

1. Potentiodynamic polarization results indicate that MBZ inhibited both cathodic and anodic reactions and acted as mixed-type inhibitor.

2. The inhibition efficiency of MBZ was dependent on the concentration of the inhibitor and the acid concentration with maximum inhibition efficiencies at higher concentrations of the inhibitor and the acid.

3. The results of SEM surface morphology, before and after the introduction of corrosion inhibitor show the extent of surface coverage of MBZ.

\section{Funding}

This research was funded by the Tertiary Education Trust Fund (TETFund), Nigeria through the Institution Based Research (IBR) Interventions.

\section{Acknowledgments}

The authors acknowledge the financial support provided for this research by the Tertiary Education Trust Fund (TETFund), Nigeria through the Institution Based Research (IBR) Interventions. A.A. Adediran appreciate Landmark University Centre for Research, Innovation and Development (LUCRID) for their support.

\section{References}

1. M.G. Fontana, Corrosion Engineering, 3rd Edition, Tata McGraw-Hill Publishing Company Ltd, New Delhi, 2005.

2. F.O. Edoziuno, A.A. Adediran, B.U. Odoni, A.D. Akinwekomi, O.S. Adesina and M. Oki, Optimization and development of predictive models for the corrosion inhibition of mild steel in sulphuric acid by methyl-5-benzoyl-2-benzimidazole carbamate (mebendazole), Cogent Eng., 2020, 7, 1714100. doi: 10.1080/23311916.2020.1714100

3. C.A. Loto, R.T. Loto, O. Osugbunu and A.P. Popoola, Corrosion inhibition effect of Allium Cepa extracts on mild steel in HCl, Pharma Chem., 2016, 8, 272-281.

4. C.A. Loto, R.T. Loto and O.O. Joseph, Effect of benzamide on the corrosion inhibition of mild steel in sulphuric acid, S. Afr. J. Chem., 2017, 70, 38-43. doi: 10.17159/03794350/2017/v70a6

5. F. El-hajjaji， I. Merimi， L. El Ouasif， M. El Ghoul， R. Achour, B. Hammouti, M.E. Belghiti, D.S. Chauhan and M.A. Quraishi, 1-Octyl-2-(octylthio)-1Hbenzimidazole as a New and Effective Corrosion Inhibitor for Carbon Steel in $1 \mathrm{M} \mathrm{HCl}$, Port. Electrochim. Acta., 2019, 37, 131-145. doi: 10.4152/pea.201903131 
6. G. Karthik and M. Sundaravadivelu, Inhibition of Mild Steel Corrosion in Sulphuric Acid Using Esomeprazole and the Effect of Iodide Ion Addition, ISRN Electrochem., 2013, 403542, 1-10. doi: 10.1155/2013/403542

7.D.S. Zinad, Q.A. Jawad, M.A.M. Hussain, A. Mahal, L. Mohamed and A.A. Al-Amiery, Adsorption, temperature and corrosion inhibition studies of a coumarin derivatives corrosion inhibitor for mild steel in acidic medium: gravimetric and theoretical investigations, Int. J. Corros. Scale Inhib., 2020, 9, no. 1, 134-151. doi: 10.17675/23056894-2020-9-1-8

8. A. Nahlé, I.I. Abu-Abdoun and I. Abdel-Rahman, Inhibition of mild steel corrosion by 3-benzoylmethyl benzimidazolium hexafluoroantimonate in acidic solution, Int. J. Corros., 2012, 246013. doi: 10.1155/2012/246013

9. A.A. Mahmmod, Experimental studies of mild steel corrosion inhibition in hydrochloric acid using inhibitor type sulfa drugs, Int. J. Corros. Scale Inhib., 2019, 8, no. 4, 11121122. doi: $10.17675 / 2305-6894-2019-8-4-18$

10. T. Peme, L.O. Olasunkanmi, I. Bahadur, A.S. Adekunle, M.M. Kabanda and E.E. Ebenso, Adsorption and corrosion inhibition studies of some selected dyes as corrosion inhibitors for mild steel in acidic medium: Gravimetric, electrochemical, quantum chemical studies and synergistic effect with iodide ions, Molecules, 2015, 20, no. 9, 16004-16029. 10.3390/molecules200916004

11. E.E. Oguzie, Y. Li and F.H. Wang, Corrosion inhibition and adsorption behavior of methionine on mild steel in sulfuric acid and synergistic effect of iodide ion, J. Colloid Interface Sci., 2007, 310, no. 1, 90-98. doi: 10.1016/j.jcis.2007.01.038

12. O.D. Onukwuli and M. Omotioma, Study of Bitter Leaves Extract as Inhibitive Agent in $\mathrm{HCl}$ Medium for the Treatment of Mild Steel through Pickling, Port. Electrochim. Acta, 2019, 37, 115-121. doi: 10.4152/pea.201902115

13. B. Anwar, T. Khairunnisa and Y. Sunarya, Corrosion inhibition of A516 carbon steel in $0.5 \mathrm{M} \mathrm{HCl}$ solution using Arthrospira platensis extract as green inhibitor, Int. J. Corros. Scale Inhib., 2020, 9, no. 1, 244-256. doi: 10.17675/2305-6894-2020-9-1-15

14. D.S. Zinad, M. Hanoon, R.D. Salim, S.I. Ibrahim, A.A. Al-Amiery, M.S. Takriff and A.A.H. Kadhum, A new synthesized coumarin-derived Schiff base as a corrosion inhibitor of mild steel surface in $\mathrm{HCl}$ medium: gravimetric and DFT studies, Int. J. Corros. Scale Inhib., 2020, 9, no. 1, 228-243. doi: 10.17675/2305-6894-2020-9-1-14

15. T.A. Salman, Q.A. Jawad, M.A.M. Hussain, A.A. Al-Amiery, L. Mohamed, A.A.H. Kadhum and M.S. Takriff, Novel ecofriendly corrosion inhibition of mild steel in strong acid environment: Adsorption studies and thermal effects, Int. J. Corros. Scale Inhib., 2019, 8, no. 4, 1123-1137. doi: 10.17675/2305-6894-2019-8-4-19

16. G. Gece, Drugs: A review of promising novel corrosion inhibitors, Corros. Sci., 2011, 53, no. 12, 3873-3898. doi: 10.1016/j.corsci.2011.08.006 
17. J.O. Okeniyi, C.A. Loto and A.P.I. Popoola, Morinda Lucida effects on steel-reinforced concrete in 3.5\% NaCl: Implications for corrosion-protection of wind-energy structures in saline/marine environments, Energy Procedia, 2014, 50, 421-428. doi: 10.1016/j.egypro.2014.06.051

18. J. Aljourani, K. Raeissi and M.A. Golozar, Benzimidazole and its derivatives as corrosion inhibitors for mild steel in $1 \mathrm{M} \mathrm{HCl}$ solution, Corros. Sci., 2009, 51, 18361843. doi: $10.1016 /$ j.corsci.2009.05.011

19. M. Yadav, D. Behera, S. Kumar and R.R. Sinha, Experimental and quantum chemical studies on the corrosion inhibition performance of benzimidazole derivatives for mild steel in $\mathrm{HCl}$, Ind. Eng. Chem. Res., 2013, 52, no. 19, 6318-6328. doi: 10.1021/ie400099q

20. Y. Tang, F. Zhang, S. Hu, Z. Cao, Z. Wu and W. Jing, Novel benzimidazole derivatives as corrosion inhibitors of mild steel in the acidic media. Part I: Gravimetric, electrochemical, SEM and XPS studies, Corros. Sci., 2013, 74, 271-282. doi: 10.1016/j.corsci.2013.04.053

21. J. Aljourani, M.A. Golozar and K. Raeissi, The inhibition of carbon steel corrosion in hydrochloric and sulfuric acid media using some benzimidazole derivatives, Mater. Chem. Phys., 2010, 121, 320-325. doi: 10.1016/j.matchemphys.2010.01.040

22. B.U. Odoni, F.O. Edoziuno and N.C. Chukwurah, Corrosion inhibition potential of methyl-5-benzoyl-2-benzimidazole carbamate (mebendazole) for mild steel in $1.0 \mathrm{~m}$ sulphuric acid, Int. J. Res. Eng. Innovation, 2017, 1, no. 6, 190-194.

23. I. Ahamad and M.A. Quraishi, Mebendazole: New and efficient corrosion inhibitor for mild steel in acid medium, Corros. Sci., 2010, 52, 651-656. doi: 10.1016/j.corsci.2009.10.012

24. A.G. Berezhnaya, V.V. Chernyavina and L.M. Astakhova, Imidazobenzimidazole hydrochloride derivatives as steel inhibitors in hydrochloric acid, Int. J. Corros. Scale Inhib., 2020, 9, no. 1, 313-319. doi: 10.17675/2305-6894-2020-9-1-20

25. F.O. Edoziuno, B.U. Odoni, A.A. Adediran, J.O. Okeniyi and E.T. Akinlabi, Analyses of the Gravimetric and Electrochemical Effects of $\mathrm{C}_{16} \mathrm{H}_{13} \mathrm{~N}_{3} \mathrm{O}_{3}$ on Mild Steel Corrosion in $0.5 \mathrm{M} \mathrm{H}_{2} \mathrm{SO}_{4}$, J. Phys.: Conf. Ser., 2019, 1378, no. 3, 032064. doi: 10.1088/1742$\underline{6596 / 1378 / 3 / 032064}$

26. O.L. Riggs Jr., Corrosion Inhibitors, 2nd edition, C.C. Nathan, Houston, TX, 1973.

27. W.N. Ahmaeed, A.N. Abd, A.A. Khadom, Corrosion inhibition effect of sodium iodide for mild steel in $1 \mathrm{M}$ hydrochloric acid: Gravimetrical and electrochemical studies, Int. J. Corros. Scale Inhib., 2019, 8, no. 4, 1097-1111. doi: 10.17675/2305-6894-2019-8-4$\underline{17}$ 